\title{
Collectif, Les vivants et les morts dans les sociétés médiévales
}

Haude Morvan

\section{(2) OpenEdition}

1 Journals

Édition électronique

URL : https://journals.openedition.org/ccm/5438

DOI : $10.4000 / \mathrm{ccm} .5438$

ISSN : 2119-1026

Éditeur

Centre d'études supérieures de civilisation médiévale/Université de Poitiers

\section{Édition imprimée}

Date de publication : 1 décembre 2020

Pagination : 310-311

ISBN : 978-2-490783-07-6

ISSN : 0007-9731

\section{Référence électronique}

Haude Morvan, "Collectif, Les vivants et les morts dans les sociétés médiévales », Cahiers de civilisation médiévale [En ligne], 252 | 2020, mis en ligne le 01 décembre 2020, consulté le 10 décembre 2022. URL : http://journals.openedition.org/ccm/5438 ; DOI : https://doi.org/10.4000/ccm.5438

\section{(c) (i) $\odot$}

Creative Commons - Attribution - Pas d'Utilisation Commerciale - Pas de Modification 4.0 International - CC BY-NC-ND 4.0

https://creativecommons.org/licenses/by-nc-nd/4.0/ 
Les vivants et les morts dans les sociétés médiévales, $48^{\mathrm{e}}$ Congrès de la Société des historiens médiévistes de l'Enseignement supérieur public (Jérusalem, 4-7 mai 2017), Paris, Éditions de la Sorbonne (Histoire ancienne et médiévale, 158), 2018.

Pour sa $48^{\mathrm{e}}$ édition, le congrès annuel de la SHMEP est revenu sur une thématique qui avait déjà été celle du congrès de 1975 (La mort au Moyen Âge, actes de colloque [Strasbourg, juin 1975], P. Chaunu [préf.], Strasbourg, Istra [Publications de la Société savante d'Alsace et des régions de l'Est, 25], 1977). Le choix de Jean-Claude Schmitt - qui faisait en 1975 une présentation sur «Le suicide au Moyen Âge »-pour signer le rapport conclusif de ce nouveau volume constitue un bel hommage à l'héritage de l'École des Annales. Depuis les années 70, marquées par le célèbre ouvrage de Philippe Ariès, L'homme devant la mort (Paris, Éditions du Seuil, 1977), la fertilité et le succès du thème de la mort au Moyen Âge, véritable carrefour de l'interdisciplinarité, sont allés croissant. La vitalité de la recherche actuelle dans ce domaine est magnifiquement illustrée par ce passionnant volume qui regroupe un vaste panel de spécialistes en histoire, en histoire de l'art et du théâtre, en archéologie, en épigraphie et en exégèse. Comme l'indique le titre, l'ambition est ici d'aborder les sociétés médiévales, chrétiennes, juives et musulmanes, depuis la Scandinavie jusqu' au Proche-Orient, depuis l'Espagne jusqu'à l'Arménie, avec un intérêt particulier pour les espaces de rencontre entre les cultures, telle que la ville de Jérusalem, choisie pour le colloque.

L'introduction de Michel Lauwers et Julien Loiseau, extrêmement riche, explicite la volonté des organisateurs d'aborder la question de la mort au Moyen Âge dans une perspective sociale. Les auteurs dressent un bilan historiographique très efficace sur les problématiques liées à la mort et à la mémoire dans les sociétés anciennes chrétiennes, juives et musulmanes. Cet état de l'art leur permet de souligner que, si la construction du programme a bien été motivée par une volonté comparatiste, il est encore trop tôt pour envisager une véritable synthèse qui engloberait l'ensemble des sociétés médiévales, en raison d'une avancée de la recherche encore inégale : il y a, en particulier, encore trop peu de données archéologiques sur les espaces funéraires musulmans et juifs par rapport aux cimetières chrétiens, bien mieux connus. De fait, seule la contribution de Marie-Anne Polo de Beaulieu sur le repos hebdomadaire des âmes en peine dans le judaïsme et le christianisme adopte une approche comparative. Néanmoins, la réunion autour d'une même thématique de contributions considérant différentes cultures, et les propositions explicites de comparaisons formulées par certains auteurs, dessinent des pistes passionnantes pour penser les parallèles et les influences réciproques quant aux pratiques et aux croyances liées à la mort. Par ex., Isabelle Augé souligne les similitudes, dans leur contenu, entre les épitaphes arméniennes qu'elle étudie et les épitaphes occidentales, tandis que Philippe Blanchard, dans une très belle synthèse sur l'archéologie des cimetières juifs médiévaux, pointe la contemporanéité d'apparition du cimetière chrétien et du cimetière juif au $\mathrm{XI}^{\mathrm{e}}$ siècle.

Les 21 contributions assez courtes qui composent le volume sont regroupées en sept thématiques transversales : « le tombeau des morts illustres », « écritures funéraires », « memoria et commémoration », « tombes et cimetières médiévaux », « préparer la mort, prendre en charge les morts ", " mourir en Terre sainte » et " les temps de l'au-delà ». Les contributions abordent les sociétés chrétiennes de l'Occident chrétien (Morgane Uberti, Régine Le Jan, Florian Mazel, Isabelle Cartron, Lucie Malbos, Didier Panfili, Pascal Montaubin, Emmanuel Bain, Marie Bouhaïk-Gironès et M.-A. Polo de Beaulieu), des États latins d'Orient (Florian Besson, Yves Gleize et al., Camille Rouxpetel), les sociétés chrétiennes orientales (Mathilde Boudier, I. Augé et Élisabeth Malamut), le monde musulman 
(Anna Caiozzo et Mathieu Tillier) et les communautés juives d'Europe (M.-A. Polo de Beaulieu, Elisheva Baumgarten, P. Blanchard et Claire Soussen). Une importance particulière a été donnée aux marches de l'Occident (telle que la Scandinavie du $\mathrm{x}^{\mathrm{e}}$ siècle, traitée par L. Malbos) et aux aires de mixité culturelle (les royaumes latins de Terre sainte, l'Espagne).

L'ensemble des contributions balaie une frange large de cette société des vivants et des morts, depuis les plus humbles dont il est question dans les chapitres sur les cimetières (E. Baumgarten, P. Blanchard, Y. Gleize et al.), les testaments (D. Panfili) et les hôpitaux (P. Montaubin), jusqu'aux puissants (É. Malamut et F. Mazel) et aux « morts illustres », personnages bibliques (A. Caiozzo), saints (M. Boudier, M. Bouhaïk-Gironès) ou chevaliers morts au cours d'une guerre sainte (F. Mazel).

Les contributions invitent à repenser les frontières et les catégories. Si la question des frontières entre les religions et les cultures est bien évidemment au cœur de l'ouvrage, sont également envisagées les frontières entre les genres (E. Baumgarten et É. Malamut), entre les groupes sociaux (D. Panfili) et entre les périodes. Les phénomènes de rupture et de continuité dans la durée sont en effet questionnés, qu'il s'agisse de la transition entre Antiquité et Moyen Âge (M. Uberti), ou entre Moyen Âge et Temps modernes (P. Blanchard). Par ailleurs, plusieurs contributions abordent en filigrane les liens entre le passé ancien et le temps présent, à travers l'effacement de la mémoire ou au contraire sa permanence. Ces liens peuvent conditionner le travail du chercheur qui travaille sur les morts : tandis que les traces de certains défunts risquent de disparaître (cf. la dégradation rapide de certaines épitaphes arméniennes dont s'alarme I. Augé), d'autres défunts, même anciens, appartiennent toujours à une communauté qui peut s'opposer à une étude impliquant un dérangement du monument funéraire et des restes (P. Blanchard).

Les contributions abordent les rapports entre les vivants et les morts non seulement à travers les textes, mais aussi à travers la culture matérielle, qu'il s'agisse du mobilier funéraire (I. Cartron) ou des différents supports de la mémoire : le livre, éventuellement enluminé (A. Caiozzo, R. Le Jan et É. Malamut), l'inscription (I. Augé, E. Baumgarten et M. Uberti), le tombeau monumental ou le reliquaire (M. Boudier et A. Caiozzo), le programme peint (F. Mazel). Par conséquent, on ne peut que regretter la carence d'illustrations. Dans les rares contributions qui comportent des figures, celles-ci sont en noir et blanc, trop peu nombreuses, et de petites dimensions, tandis que plusieurs chapitres pourtant basés sur des sources iconographiques sont étonnamment dépourvus d'illustrations (par ex. A. Caiozzo et F. Mazel).

Cet ouvrage n'en reste pas moins une très belle réussite. Il montre de manière magistrale combien, quarante ans après L'homme devant la mort de P. Ariès, la question de la mort dans les sociétés médiévales reste encore un terrain de recherche où de nombreuses pistes sont à explorer.

Haude Morvan UMR 5607

Université Bordeaux Montaigne,

Institut Ausonius 